\title{
Mechanism by Which Indomethacin Delays Gastric Ulcer Healing in the Rat: Inhibited Contraction of the Ulcer Base
}

\author{
Yoshiyasu Ogihara and Susumu Okabe* \\ Department of Applied Pharmacology, Kyoto Pharmaceutical University, Misasagi, Yamashina, Kyoto 607, Japan
}

Received September 2I, 1992 Accepted November 24, 1992

\begin{abstract}
Repeated administration of indomethacin delays the healing of acetic acid-induced gastric ulcers in rats, but the underlying mechanism remains unclear. We examined the effect of indomethacin on the contraction of the connective tissue isolated from the base of 1-week-old ulcers. The tissue samples, suspended in an organ bath, were contracted by serotonin, bradykinin and carbachol and also slightly contracted by prostaglandin (PG) $\mathrm{F}_{1 \alpha}$. The effect of serotonin was the most potent. However, 6-keto-PGF ${ }_{1 \alpha}$, $\mathrm{PGE}_{2}$ and histamine had little or no contraction inducing effect. The contractile response to serotonin of the tissue in the indomethacin-treated group was significantly less than that in the control group (without indomethacin treatment). After a 2-week treatment with indomethacin, a histological study of the ulcers showed that the length of rupturing of the muscularis mucosa was significantly greater than that observed in the control group. However, indomethacin had no effect on the length of the regenerated mucosa and the thickness of the ulcer base. We conclude that the connective tissue at the ulcer base has the ability to contract and that the prevention of the contraction of the tissue by indomethacin might be involved in the mechanism underlying delayed ulcer healing.
\end{abstract}

Keywords: Ulcer (acetic acid-induced), Indomethacin, Delayed-healing, Connective tissue, Contraction of ulcer base

The healing process in the case of penetrating gastric ulcers consists of epithelization from the edge of the ulcers and contraction of the ulcer base (1), being very similar to general wound healing $(2,3)$. However, it is unknown whether or not the contraction involves contraction of the connective tissue at the ulcer base or that of smooth muscle around the ulcer crater. Chronic treatment with various anti-inflammatory drugs apparently delays the healing of gastric ulcers induced in the rat (4-7). In our histologic study, a marked reduction in ulcer size was observed in the control group with the buildup of granulation tissue to nearly the level of the surrounding mucosa (8). In contrast, the ulcer base in animals treated with indomethacin was flat and large, consisting of irregularly-developed connective tissue. There was no sign of contraction of these connective tissues. These findings strongly suggested that the mechanism by which indomethacin delays ulcer healing might partly involve the prevention of contraction of the connective tis-

\footnotetext{
* To whom correspondence should be addressed.
}

sue at the ulcer base. In the present study, we focused on the possible contraction of connective tissue at the ulcer base as well as the contraction of smooth muscle. Therefore, we first determined if the connective tissue isolated from the ulcer base has an ability to contract in response to various agents; and second, we observed whether treatment with indomethacin suppresses the contractile response of the connective tissue.

\section{MATERIALS AND METHODS}

\section{Animals}

Male Donryu strain rats (Nihon SLC), weighing 240$260 \mathrm{~g}$, were used. The rats were not fasted prior to ulcer production to facilitate the injection of the acetic acid solution into the gastric wall. Before the autopsy, the rats were fasted for $18 \mathrm{hr}$ in raised mesh bottom cages with free access to tap water.

\section{Induction of gastric ulcers}

Gastric ulcers were induced by the previously reported 
method $(6,9)$. Briefly, under ether anesthesia, the abdomen was incised and the stomach exposed. Then, $20 \%$ acetic acid $(0.075 \mathrm{ml})$ was injected into the submucosal layer between the antrum and corpus of the anterior wall of the stomach. The reason that such a volume of acetic acid solution was used was to obtain a larger tissue from the ulcer base for easier determination of contraction. After closure of the abdomen, the animals were caged and maintained in the usual manner. Since well-defined and deep ulcers were observed 5 days after the acid injection, we defined the 5th day as the day of ulceration. Indomethacin was administered s.c. at $1 \mathrm{mg} / \mathrm{kg}$ once daily from the day of ulceration for 1 or 2 weeks. Control animals received the vehicle alone.

\section{Determination of contractile responses of the connective tissue and smooth muscle}

Twenty-four hours after the final administration of indomethacin or the vehicle alone for 1 or 2 weeks, the animals were killed under ether anesthesia and their stomachs removed. Each stomach was incised along the greater curvature and pinned on a cork mat immersed in Tyrode's solution. The composition of the latter solution was as follows: $8.0 \mathrm{~g} / 1 \mathrm{NaCl}, 0.2 \mathrm{~g} / 1 \mathrm{KCl}, 0.1 \mathrm{~g} / 1 \mathrm{MgCl}_{2}$, $0.2 \mathrm{~g} / 1 \mathrm{CaCl}_{2}, 0.05 \mathrm{~g} / 1 \mathrm{NaH}_{2} \mathrm{PO}_{4}, 1.0 \mathrm{~g} / 1 \mathrm{NaHCO}_{3}$ and $1.0 \mathrm{~g} / \mathrm{l}$ glucose. The solution was maintained at $37^{\circ} \mathrm{C}$ and continuously aerated with $95 \% \mathrm{O}_{2}-5 \% \mathrm{CO}_{2}$. Connective tissue at the ulcer base was isolated from the surrounding tissues under a dissecting microscope (Olympus, $\times 10$ ) as follows: The hepatic tissue adhering to the ulcer base was removed, and then about $1 \mathrm{~cm}^{2}$ of the stomach was dis- sected away. The gastric mucosa around the ulcer, muscle and necrotic layer covering the ulcer base were removed using ophthalmic scissors. The connective tissue at the ulcer base occupies the whole stomach wall thickness and is apparently harder than the surrounding normal mucosa and muscle. Therefore, the isolation of the tissue alone, i.e., without including the smooth muscle, is not difficult. The strips $(10-15 \times 2 \mathrm{~mm})$, which were cut from the isolated tissue, were then immersed in a $10-\mathrm{ml}$ organ bath containing Tyrode's solution and aerated with $95 \% \mathrm{O}_{2}$ $-5 \% \mathrm{CO}_{2}$ (Fig. 1). One end of each tissue strip was attached to an immobile support, and the other end was attached to a force-transducer (UM-203; Kishimoto) connected to a recorder (D-2000; Hitachi). Contractile responses were recorded under isometric conditions. The tissues were allowed to equilibrate for $60-120 \mathrm{~min}$ prior to the treatment with drugs. During the equilibration period, the tissues were gently stretched to obtain an appropriate resting tension. The resting tension of these strips was $500 \mathrm{mg}$. Serotonin, bradykinin, carbachol, prostaglandin $(\mathrm{PG}) \mathrm{F}_{1 \alpha}$, 6-keto-PGF $\mathrm{PG}_{1 \alpha}, \mathrm{PGE}_{2}$ and histamine at the final concentrations of $10^{-7}-10^{-5} \mathrm{~g} / \mathrm{ml}$ were used to determine the contractile responses. Concentration-response curves were obtained by exposing the tissues to drugs in a cumulative manner, the responses being expressed as $\mathrm{mg}$ tension/ $\mathrm{mm}$ strip length. After the experiments, the tissues isolated from the ulcer base were put in $10 \%$ formalin, embedded into paraffin, sectioned ( $4 \mu \mathrm{m})$ and then stained with azan to determine if the strips contained a smooth muscle layer. When the strip was found not to contain any smooth muscle layer, the data were
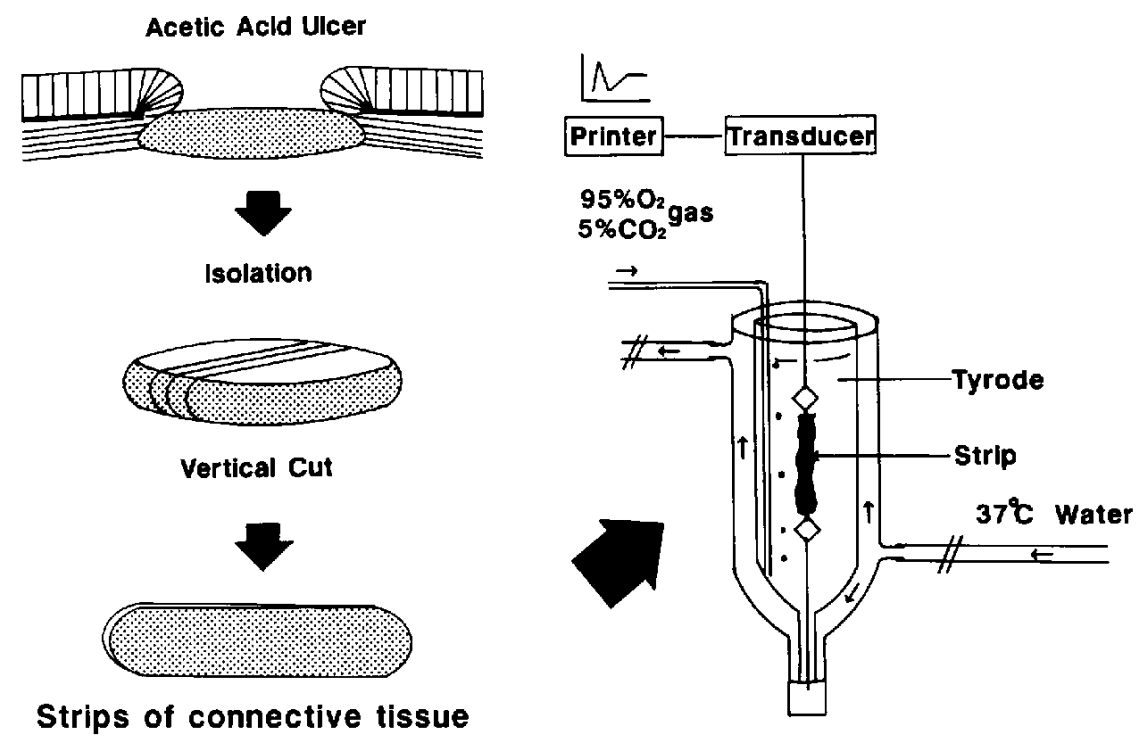

Fig. 1. Schematic illustration of the method used for determination of the contractile response of the granulation tissue at the ulcer base. The contractile response was isometrically determined in the water bath. 
used for evaluation of the contractile responses.

Like the experiments on connective tissue, the effects of the above agents on longitudinal strips, including the mucosal layer, of the corpus isolated from normal stomachs (without ulceration) treated with or without indomethacin for 1 week were studied as well. These strips were also suspended in an organ bath, and the contraction in response to the above agents was determined.

\section{Histological studies}

It is well-known that the muscularis mucosa ruptured by ulceration does not regenerate (10). Therefore, the length of the ruptured muscularis mucosa can be used as an index of the contraction at the ulcer base. The length of the ruptured muscularis mucosa $(\mathrm{mm})$, the length of the regenerated gastric mucosa $(\mathrm{mm})$ and the thickness of the ulcer base ( $\mathrm{mm}$ ) in groups treated with and without indomethacin were determined (Fig. 2). The animals were killed at 0,1 or 2 weeks after the day of ulceration and their stomachs removed. Each stomach was incised along the greater curvature and then the ulcerated area $\left(\mathrm{mm}^{2}\right)$ was determined under a dissecting microscope $(\times 10)$. After fixation of the stomach in $10 \%$ formalin, the tissue was embedded in paraffin, sectioned $(4 \mu \mathrm{m})$ and stained with azan. The histological indices were determined under a light microscope (Olympus, $\times 40$ ) with a grid. The persons who measured the ulcerated area and histological indices were unaware of which treatment the animals had been given.

\section{Drugs}

Indomethacin was suspended in saline with a trace of Tween-80. Indomethacin was prepared immediately be- fore use and administered in a volume of $0.5 \mathrm{ml}$ per $100 \mathrm{~g}$ body weight. The drugs used in vitro were serotonincreatinine-sulfate, bradykinin, $\mathrm{PGE}_{2}, \mathrm{PGF}_{1 \alpha}$, 6-keto$\mathrm{PGF}_{1 \alpha}$, histamine dihydrochloride and carbachol (Sigma). These drugs were dissolved into Tyrode's solution and added to the bath in a volume of $100 \mu \mathrm{l}$. The concentration of each drug was expressed in terms of the base.

\section{Statistics}

All data represent means \pm S.E.M. Dunnett's multiple comparison test or Student's $t$-test was used to determine the statistical significance of differences, and a $P$ value of $<0.05$ was regarded to indicate a significant difference.

\section{RESULTS}

\section{Effect of indomethacin on ulcer healing}

Within a few days after the acid injection, there was free perforation of the ulcer base, the incidence being about $10 \%$. Five days later, there were well-defined deep ulcers in all animals that survived. The ulcerated area at the day of ulceration was $41.7 \pm 3.0 \mathrm{~mm}^{2}(\mathrm{~N}=12)$ (Fig. 3). These ulcers spontaneously diminished in size, the ulcerated areas at 1 and 2 weeks being $22.2 \pm 3.5$ and $7.9 \pm 0.4$ $\mathrm{mm}^{2}(\mathrm{~N}=12)$, respectively. Treatment with indomethacin for 1 and 2 weeks significantly delayed the healing of gastric ulcers, the ulcerated area at 1 and 2 weeks being $35.4 \pm 4.5$ and $14.4 \pm 1.8 \mathrm{~mm}^{2}(\mathrm{~N}=12)$, respectively.

\section{Contractile response of the connective tissue or corpus}

The isolation of connective tissue from the ulcer base at 1 week was rather easy because of its size (about $30 \mathrm{~mm}^{2}$ ) in both the control and indomethacin-treated groups.

\section{Acetic Acid Ulcer}
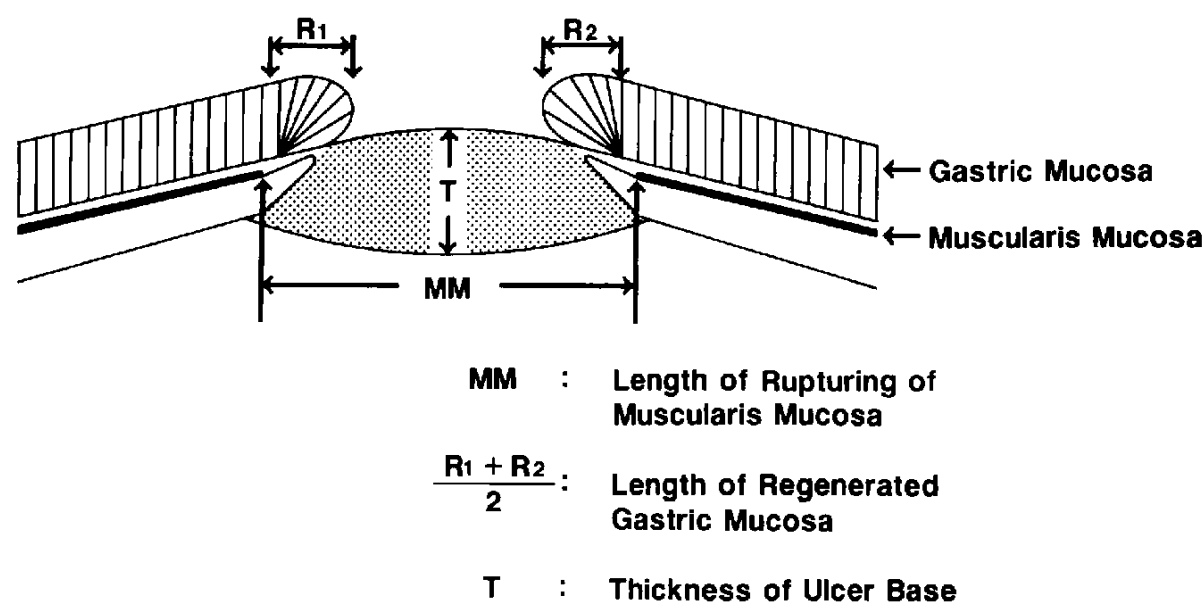

Fig. 2. Histological indices for acetic acid-induced gastric ulcers. 

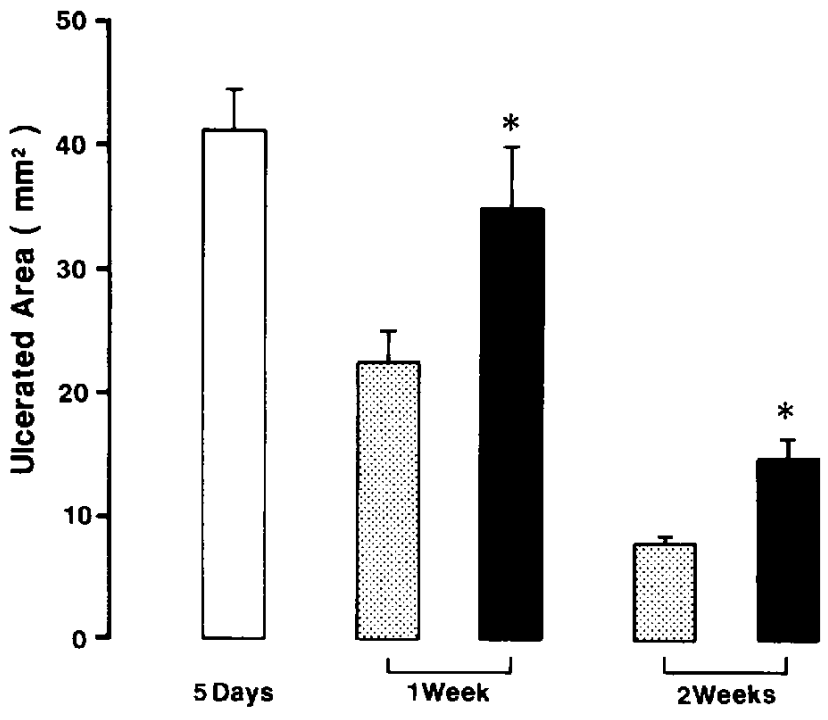

Fig. 3. Effect of indomethacin on the healing of acetic acid-induced gastric ulcers in rats. Note that the treatment with indomethacin significantly delayed the healing of gastric ulcers. Data are means \pm S.E.M. $(n=12)$. *Statistically significant difference from the control group at $\mathrm{P}<0.05$. . Control, $\square$ : Indomethacin.

However, the 2-week-old ulcers in the control group were rather small due to the advanced healing so the isolation of sufficient ulcer tissue to determine the contraction was difficult. Therefore, in the present study, we examined the contractile responses of only the tissues isolated from 1-week-old ulcers. Typical records of the contraction caused by various chemical agents are shown in Figs. 4 and 5. The strips in both the control and indomethacintreated groups contracted by serotonin, bradykinin and carbachol at $10^{-7}$ to $10^{-5} \mathrm{~g} / \mathrm{ml}$. The order of the contractile potency was serotonin $>$ bradykinin $>$ carbachol. $\mathrm{PGF}_{1 \alpha}$ contracted the strips only slightly, even at $10^{-5}$ $\mathrm{g} / \mathrm{ml}$. On the other hand, $\mathrm{PGE}_{2}, 6-$ keto-PGF $_{1 \alpha}$ and histamine were unable to contract the strips. Since the contractile response caused by serotonin was the most stable and strongest, we used serotonin in the following experiments.

The concentration response curves of serotonin in the control and indomethacin-treated groups at 1 week are shown in Fig. 6. The contractile tension with $10^{-5} \mathrm{~g} / \mathrm{ml}$ in the control and indomethacin-treated groups was $9.2 \pm 1.3$ and $5.6 \pm 1.0 \mathrm{mg} / \mathrm{mm}$ strip length, respectively. The tension in response to serotonin at $10^{-7}$ to $10^{-5} \mathrm{~g} / \mathrm{ml}$ in the indomethacin-treated group was significantly less compared with that in the control group. The doses of serotonin producing $50 \%$ contraction in the control and indomethacin-treated groups were $9.7 \times 10^{-7}$ and $1.1 \times$ $10^{-6} \mathrm{~g} / \mathrm{ml}$, respectively. These values were not statistical-

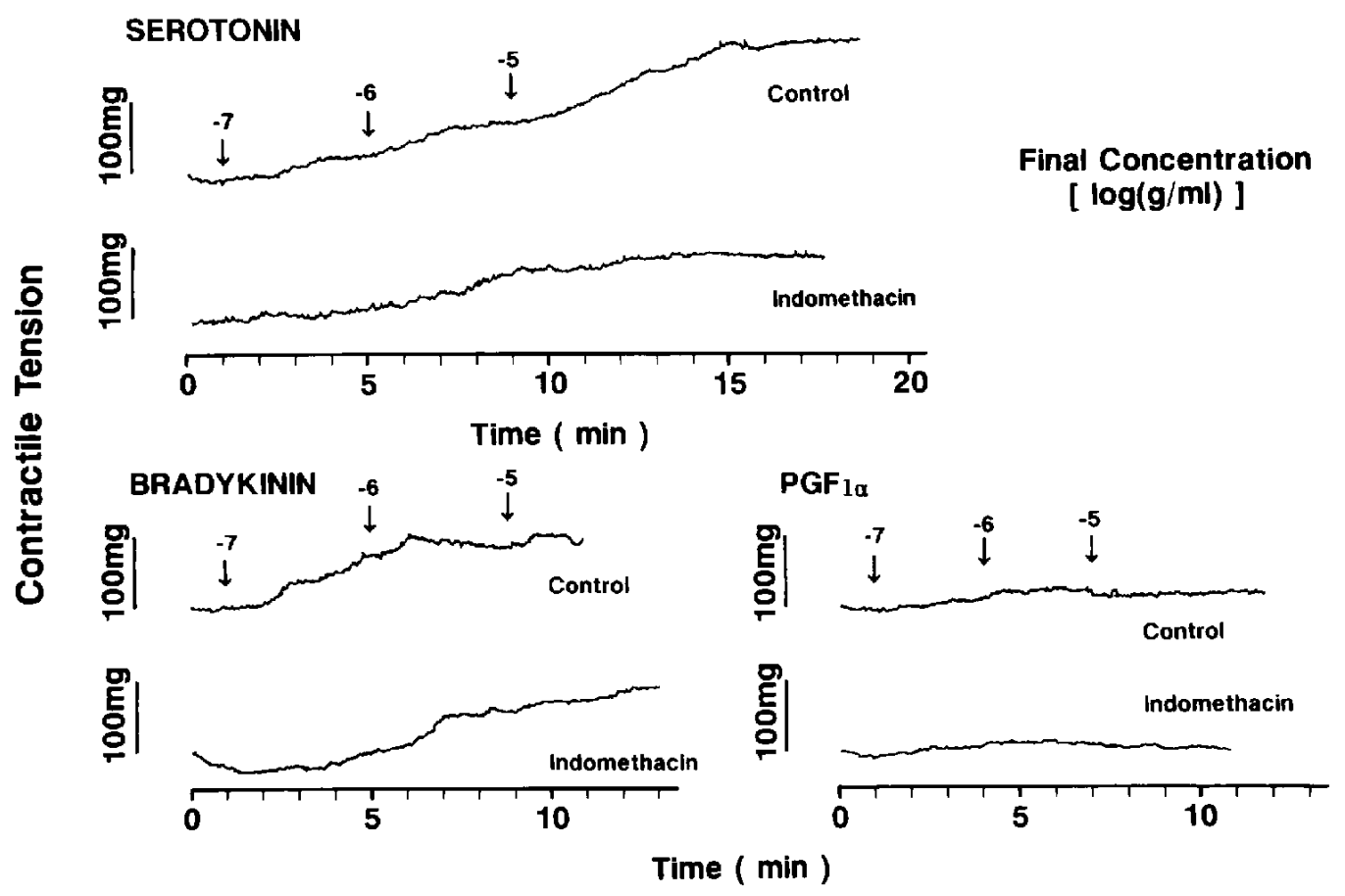

Fig. 4. Typical records of the contractile responses of the granulation tissue isolated from the ulcer base. The agents were applied to the tissue, in a cumulative manner, at each arrow. Note that the strips in both the control and indomethacin-treated groups were contracted by serotonin and bradykinin. $\mathrm{PGF}_{1 \alpha}$ slightly contracted the granulation tissue. 


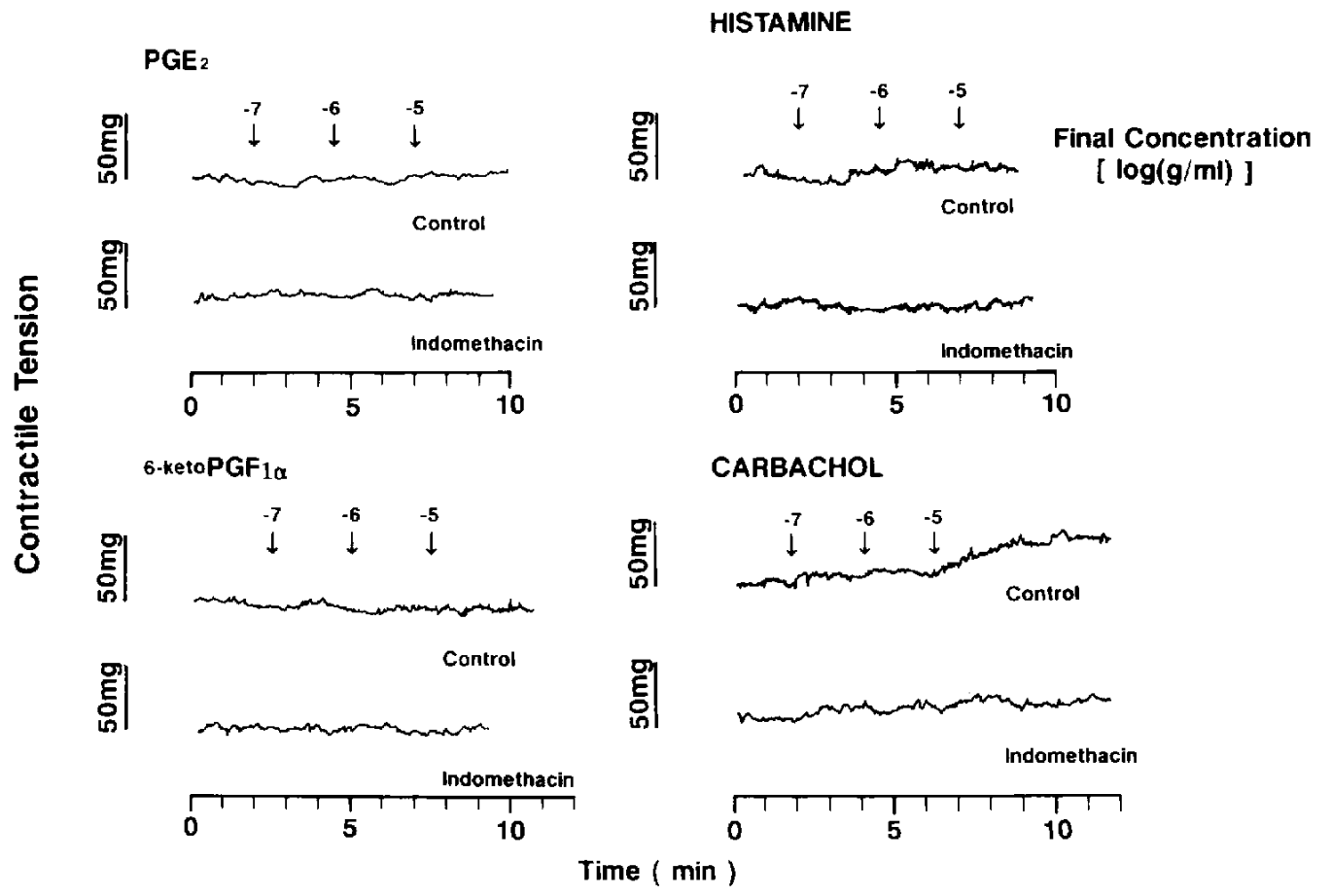

Fig. 5. Typical records of the contractile responses of the granulation tissue isolated from the ulcer base. The agents were applied to the tissue, in a cumulative manner, at each arrow. Note that the strips in both the control and indomethacin-treated groups were contracted carbachol, but not by $\mathrm{PGE}_{2}, 6-$ keto-PGF $_{1 \alpha}$ and histamine.

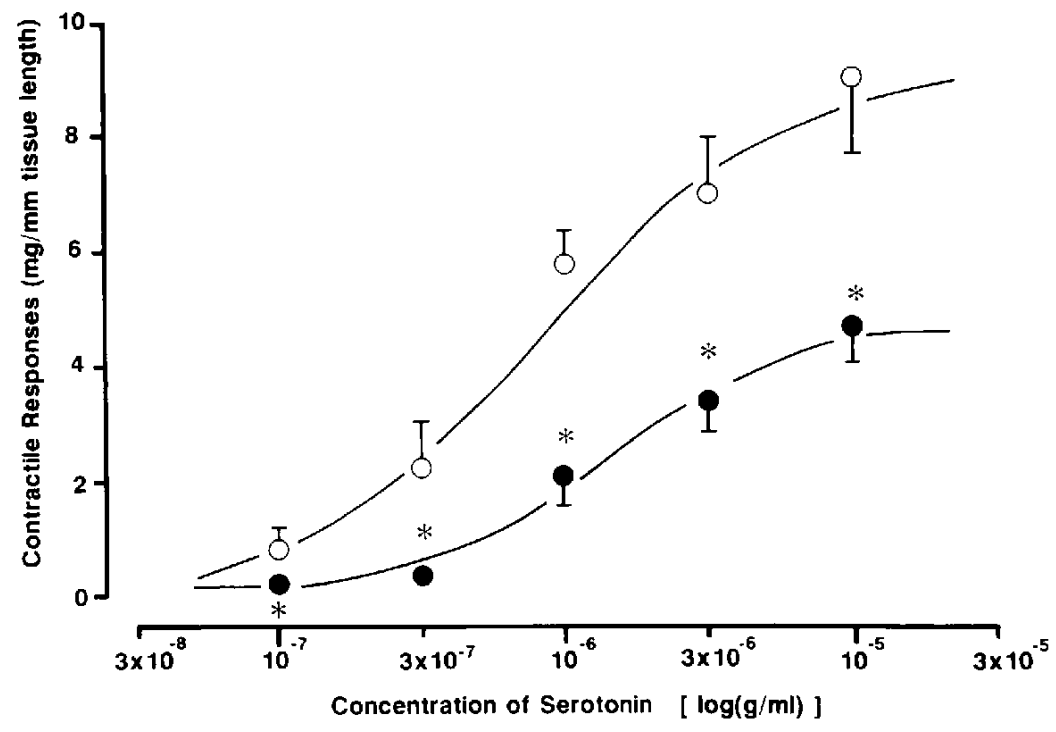

Fig. 6. Cumulative concentration curves in response to serotonin. Note that the contractile tension in the indomethacintreated group was significantly less than that observed in the control group. Data are means \pm 1 S.E.M. (n=12). *Statistically significant difference from the control group at $P<0.05 . \bigcirc$ : Control, $O$ : Indomethacin.

ly different. Histologically, the isolated strips did not contain any smooth muscle layer (Fig. 7).

The corpus longitudinal muscle in the control group was contracted by serotonin, bradykinin, $\mathrm{PGF}_{1 \alpha}$ and car- bachol in a concentration-dependent manner (Fig. 8). Almost similar contraction was observed in the indomethacin-treated group. 


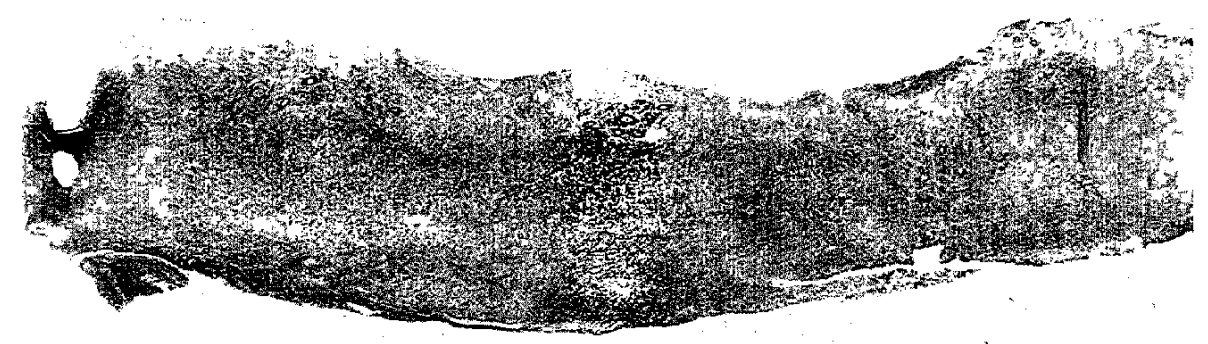

Fig. 7. Microscopic observation of an isolated strip from the base of an acetic acid-induced gastric ulcer (azan). Note that the tissue did not contain any smooth muscle layer.

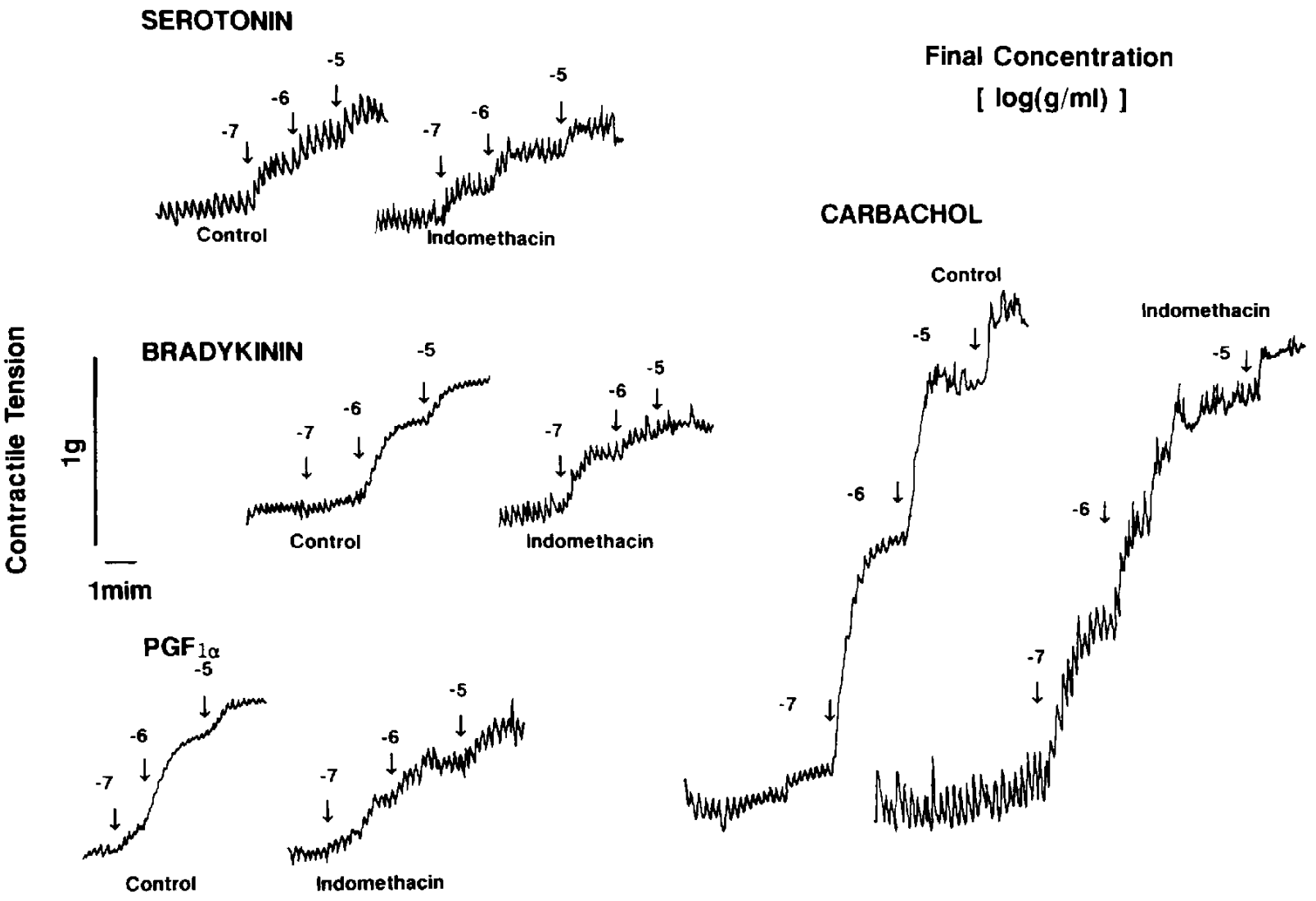

Fig. 8. Typical records of the contractile responses of the corpus longitudinal strip. The agents were applied to the tissue, in a cumulative manner, at each arrow. Note that the strips were contracted by serotonin, bradykinin and PGF $_{1 u}$ and carbachol. Indomethacin treatment did not have any influence on these contractile responses. 
Length of Rupture of

Muscularis Mucosa

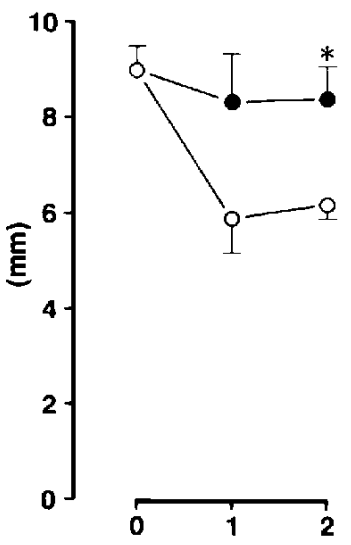

Length of Regenerated

Gastric Mucosa

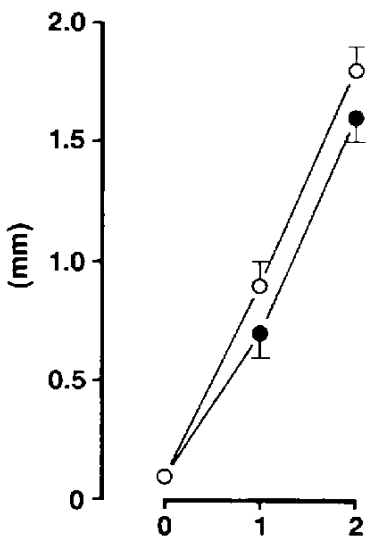

Thickness of

Ulcer Base

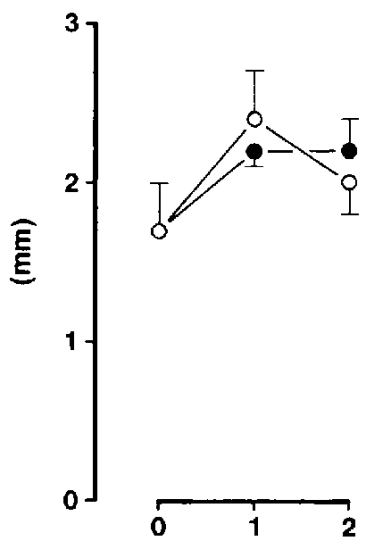

Weeks After Ulceration

Fig. 9. Effects of indomethacin on the histological indices for acetic acid-induced gastric ulcers. Note that the reduction in the ruptured length of the muscularis mucosa was apparently prevented by the repeated doses of indomethacin. Data are means \pm I S.E.M. $(n=8)$. * Statistically significant difference from the control group at $P<0.05 . \bigcirc$ : Control, $O$ : Indomethacin.

\section{Histological studies}

On the day of ulceration, the length of rupturing of the muscularis mucosa, the length of the regenerated gastric mucosa and the thickness of the ulcer base were $9.0 \pm 0.5$, $0.1 \pm 0.01$ and $1.7 \pm 0.3 \mathrm{~mm}$, respectively (Fig. 9). The length of rupturing of the muscularis mucosa decreased with time, the lengths at 1 and 2 weeks being $6.0 \pm 0.2$ and $6.2 \pm 0.3 \mathrm{~mm}$, respectively. Indomethacin treatment significantly prevented this decrease at 2 weeks, the length being $8.4 \pm 0.7 \mathrm{~mm}$. The length of the regenerated mucosa increased after the day of ulceration, the values at 1 and 2 weeks being $0.9 \pm 0.1$ and $1.8 \pm 0.1 \mathrm{~mm}$, respectively. Indomethacin, however, had no effect on these values. The thickness of the ulcer base did not change during the experimental period in either the control or indomethacintreated group.

\section{DISCUSSION}

The present study once again confirmed that the repeated administration of indomethacin significantly delays the healing of acetic acid-induced gastric ulcers. We previously reported that the delay in ulcer healing was not significant when the agent was administered for 1 week, but became significant after a 2 -week treatment (8). In this study, however, we found that the healing of ulcers was significantly delayed even after a 1-week treatment with the agent. This difference may be accounted for by the difference in ulcer size at the time of ulceration $(41.7 \pm 0.7$ vs. $33.4+3.5 \mathrm{~mm}^{2}$ in the former study) due to the differ- ent volumes of the acetic acid solution injected. Larger ulcers appear to be more extensively influenced by indomethacin.

Majno et al. $(11,12)$ were the first to demonstrate in in vitro experiments that the granulation tissue isolated from a dermal wound exhibits the ability to contract in response to serotonin, bradykinin and $\mathrm{PGF}_{1 \alpha}$. They suggested that this contractile force, which is probably due to myofibroblasts, may participate in the early stages of wound healing. However, Ehrlich (13) showed that the contraction of the granulation tissue in a dermal wound is caused by the fibroblasts and not myofibroblasts. Moore et al. (14) showed that intestinal repair was aided by villus contraction and that the subepithelial network of myofibroblasts was responsible for this process. Interestingly, Nakamura et al. (15) histochemically demonstrated the existence of myofibroblasts in the granulation tissue during the healing of acetic acid-induced gastric ulcers in rats. It appears that the connective tissue at the ulcer base also exhibits the ability to contract, similar to the cases of those obtained from dermal and intestinal wounds.

As expected, the tissue isolated from the ulcer base in the control group was contracted by serotonin, bradykinin and carbachol, and was also slightly contracted by $\mathrm{PGF}_{1 \alpha}$, confirming the observation of Majno et al. (11, 12 ) as to wound healing. To our knowledge, this is the first demonstration that the ulcer base has the ability to contract in response to certain agents. This finding strongly suggests that the healing of gastric ulcers might involve the contraction of the connective tissue present at the 
ulcer base. Joyce et al. (16) showed that the amounts of several proteins necessary for contraction, such as actin, are less in myofibroblasts than in smooth muscle. This would be the reason why the concentration of agents that caused the contraction of the connective tissue isolated from the ulcer base was apparently higher than that for the contraction of the gastric smooth muscle. Histologically, the isolated connective tissue did not contain any smooth muscle layer. Even functionally, it was clear that the tissue included no smooth muscle layer, because histamine had no effect on the isolated granulation tissue.

Of interest is that all these agents are known to be inflammation derived substances. Therefore, it is likely that several endogenous agents present in the granulation tissue might contribute to the contraction of the ulcer base to accelerate healing. If so, indomethacin might prevent the formation of these agents, including PGs, in the connective tissue. Indomethacin, which is known as a cyclooxygenase inhibitor, potently and persistently decreases the mucosal PG contents around gastric ulcers (6), most probably leading to reduced gastric mucosal blood flow (17). Therefore, the mechanism of action of indomethacin in delayed ulcer healing is considered to be partly related to the deficiency of endogenous PGs in the gastric mucosa $(5,6)$. While we did not determine the $P G$ contents in the connective tissue at the ulcer base, it is likely that the PG contents might be extensively reduced even in this tissue. It should be noted, however, that the isolated connective tissue was not caused to contract by $\mathrm{PGE}_{2}$, which promoted the healing of gastric ulcers in rats (6), or 6-keto-PGF $F_{1 \alpha}$. In addition, in our preliminary experiments, the addition of indomethacin at $10^{-5} \mathrm{~g} / \mathrm{ml}$ to the water bath did not have any influence on the contraction of granulation tissue caused by serotonin (S. Okabe et al., unpublished data). Therefore, the participation of endogenous PGs in the connective tissue is considered to be less in the contractile events during the healing of gastric ulcers.

The most important observation in this study was that the connective tissue in the indomethacin-treated group exhibited significantly lower contractile activity compared with the control group. This decrease of contractile force might be related to the mechanism by which indomethacin delays the gastric ulcer healing. The reason why indomethacin decreased the contractile activity of connective tissue can be interpreted in several ways as follows: We previously reported that treatment with indomethacin increased the collagen contents and caused the irregular development of fibrosis in the connective tissue (8). Therefore, one consideration is that this exceeded fibroplasia may interfere with the contractile response. In fact, the present study indicated that there was no difference in doses producing $50 \%$ contraction for serotonin between the control and indomethacin-treated groups. These data suggest that the sensitivity to serotonin was not different in these two groups. Another explanation for the inhibition of contraction by indomethacin is that the agent might affect the development of myofibroblasts and/or fibroblasts. Jester et al. (18) suggested that during wound healing, there is no overall increase in the actin pool, but rather a shift in the maturation of actin from unpolymerized G-actin to filamentous F-actin, which exhibits high potency as to the contraction of myofibroblasts. There is a possibility that indomethacin inhibits this transferability. Tarnawski's group suggested that the mechanism underlying delayed healing of acetic acid-induced ulcers caused by indomethacin comprises prevention of angiogenesis in the ulcer base (19). It is likely that the reduced angiogenesis in the connective tissue is associated with the reduced contractile force because of an insufficient supply of energy.

Histologically, we reconfirmed our previous findings (8) that the length of ruptured muscularis mucosa in rats treated with indomethacin was significantly larger than that observed in the control groups. These results appear to support our hypothesis that indomethacin treatment prevents the contraction of the ulcer base, leading to delayed ulcer healing. Levi et al. (20) reported that indomethacin inhibited the proliferation of mucosal cells around the cryoprobe-induced gastric ulcers in the rat. In the present study, we found that indomethacin had no effect on mucosal regeneration. It is unknown whether or not this difference is due to the difference in the dose of indomethacin used ( $2 \mathrm{vs.} 1 \mathrm{mg} / \mathrm{kg}$ in our study) or the ulcerated area (the area being about $4.5 \mathrm{~mm}^{2}$ at 5 days after ulceration vs. about $42 \mathrm{~mm}^{2}$ in our study).

One of the present authors (S.O.) reported that propantheline bromide significantly delayed the healing of acetic acid-induced ulcers in rats (21). It is possible that the underlying mechanism involves the inhibition of the contraction of smooth muscle around the ulcer crater and the connective tissue at the ulcer base. Treatment with indomethacin for 1 week of animals without ulcers did not have any influence on the contraction of fundic strips. Therefore, the mechanism underlying delayed ulcer healing caused by the agent seems to be unrelated to the contractile force of the smooth muscle around an ulcer.

We conclude that the mechanism of action of indomethacin in delayed ulcer healing might be partly related to the inhibited contraction of the ulcer base.

\section{Acknowledgment}

Part of this work was supported by a Grant-in-Aid from the Ministry of Education, Science and Culture, Japan (\# 04807161). 


\section{REFERENCES}

1 Boyd, J.S. and Wormsley, K.G.: Etiology and pathogenesis of peptic ulcer. In Gastroenterology, Edited by Berk, J, Haubrich, W.S., Kalser, M.H., Roth, J.L.A. and Schaffner, F., Vol. 2, pp. 1013-1059, Saunders, Philadelphia (1985)

2 Montandon, D., D'Andiran, G. and Gabbiani, G.: The mechanism of wound contraction and epithelialization. Clin. Plast. Surg. 4, 325-345 (1977)

3 Viljanto, J., Rajamäki, A., Renvall, S. and Raekallio, J.: Cell aggregation centers - Initial strength elements in human wound healing. J. Surg. Res. 29, 414-421 (1980)

4 Okabe, S., Saziki, R. and Takagi, K.: Cortisone acetate and stress on the healing process of chronic gastric ulcer in rats. J. Appl. Physiol. 30, 793-796 (1971)

5 Szelenyi, I., Engler, H., Herzog, P., Postius, S., Vergin, H. and Holtermüller, K.: Influence of nonsteroidal anti-inflammatory compounds on healing of chronic gastric ulcers in rats. Agents Actions 12, 180- 182 (1982)

6 Wang, J.Y., Yamasaki, S., Takeuchi, K. and Okabe, S.: Delayed healing of acetic acid-induced gastric ulcers in rats by indomethacin. Gastroenterology 96, 393-402 (1989)

7 Konturek, S.J., Brozozowski, T., Drozdowicz, D., Dembinski, A. and Nauert, C.: Healing of chronic gastroduodenal ulcerations by antacids: Role of prostaglandins and epidermal growth factor. Dig. Dis. Sci. 35, 1121-1129 (1990)

8 Ogihara, Y., Fuse, Y. and Okabe, S.: Effects of indomethacin and prednisolone on connective tissue at the base of acetic acidinduced gastric ulcers in rats. In Mechanisms of Injury, Protection and Repair of the Upper Gastrointestinal Tract, Edited by Garner, A. and O'Brien, P.E., pp. 455-465, Wiley Publishers, Chichester (1991)

9 Takai, K., Okabe, S. and Saziki, R.: A new method for the production of chronic gastric ulcer in rats and the effect of several drugs on its healing. Japan. J. Pharmacol. 19, 418-426 (1969)

10 Ivy, A.C., Grossman, M.I. and Bachrach, W.H.: Healing of acute and chronic ulcers. In Peptic Ulcer, Edited by Ivy, A.C., Grossman, M.I. and Bachrach, W.H., pp. 116-168, Blackiston, Philadelphia (1950)

11 Majno, G., Gabbiani, G., Hirschel, B.J., Ryan, G.B. and
Statkov, P.R.: Contraction of granulation tissue in vitro: Similarity to smooth muscle. Science $173,548-550$ (1971)

12 Majno G., Ryan, G.B., Gabbiani, G., Hirschel, B.J., Irle, C. and Joris, I.: Contractile events in inflammation and repair. In Inflammation. Mechanism and Control, Edited by Lepow, I.H. and Ward, P.A., pp. 13-27, Academic Press, New York (1972)

13 Ehrlich, H.P.: Wound closure: Evidence of cooperation between fibroblast and collagen matrix. Eye 2, 149-157 (1988)

14 Moore, R., Carlson, S. and Madara, J.L.: Villus contraction aids repair of intestinal epithelium after injury. Am. J. Physiol. 257, G274-G283 (1989)

15 Nakamura, M., Oda, M., Nishizaki, Y., Kaneko, K., Azuma, T. and Tsuchiya, M.: Fluorescent histochemical study on the localization of myofibroblasts in the healing of acetic acidinduced gastric ulcers in the rat. Scand. J. Gastroenterol. 24, $150-153$ (1989)

16 Joyce, N.C., Haire, M.F. and Palade, G.E.: Morphologic and biochemical evidence for contractile cell network within the rat intestinal mucosa. Gastroenterology 92, 68-81 (1987)

17 Hirose, H., Takeuchi, K. and Okabe, S.: Effect of indomethacin on gastric mucosal blood flow around acetic acid-induced gastric ulcers in rats. Gastroenterology 100, 1259-1265 (1991)

18 Jester, V.J., Rodrigues, M.M. and Herman, I.M.: Characterization of avascular corneal wound healing fibroblasts: New insight into the myofibroblast. Am. J. Pathol. 127, 140-148 (1987)

19 Tarnawski, A., Stachura, J., Douglass, T.G., Krause, W.J., Gergely, H. and Sarfeh, I.J.: Indomethacin impairs quality of experimental gastric ulcer healing: A quantitative histological and ultrastructural analysis. In Mechanisms of Injury, Protection and Repair of the Upper Gastrointestinal Tract, Edited by Garner, A. and O'Brien, P.E., pp. 521-531, Wiley Publishers, Chichester (1991)

20 Levi, S., Goodlad, R.A., Lee, C.Y., Stamp, G, Walport, M.J., Wright, N.A. and Hodgson, H.J.F.: Inhibitory effect of nonsteroidal anti-inflammatory drug on mucosal cell proliferation associated with gastric ulcer healing. Lancet 336, 840-843 (1990)

21 Okabe, S. and Pfeiffer, C. J.: Effects of propantheline bromide and milk plus cheese on healing of chronic gastric ulcers in rats. Am. J. Dig. Dis. 1, 746-750 (1973) 